past few years have seen the introduction of a new range of techniques in mammalian cytogenetics, e.g. G-banding, C-banding, R-banding, and T-banding. Chapter 1 expertly elucidates the different merits of some of these techniques in an easily readable manner. The author has some interesting points to make with regard to interspecific and intraspecific comparisons. In Chapter 2 the chromosomal characteristics of man and the anthropoid primates are enumerated and discussed with respect to phylogenetic significance. Chapter 3 illustrates the usefulness, in evolutionary terms, of an analysis of repetitive DNA differences between species. Findings substantiate the argument that the ancestor to the gibbon diverged from the higher primate stock before divergence of the common progenitor of the other higher primates. Support is also given to the views that the Asiatic apes are more distant from man than are the African apes and that the separation time between the chimpanzee and the orang-utang may have been just as long as that between man and the chimpanzee. There do, however, seem to be important differences in the rate of change between ribosomal genes (28S) and 'unique genome' DNA. The contribution of somatic cell hybridization to genetic analysis in man is reviewed in Chapter 4. The possible evolutionary significance of these findings is discussed. It is probable that gene localization studies will prove fundamental to an understanding of evolutionary processes in man.

Chapter 5 discusses environmental agents that result in chromosome damage in somatic tissues in vivo. This review is comprehensive and of particular interest to the medical practitioner concerned with the use of ionizing radiation, non-ionizing radiation (e.g. ultrasound), and chemical mutagens. The next chapter, which makes stimulating reading, is essentially a quantitative assessment of the part played by chromosomal aberration in prenatal loss in man. The author points out that many of the environmental factors believed to be associated with a raised incidence of chromosome abnormality have arisen in recent times and in the developed countries. The final chapter deals with the frequency and type of chromosome abnormality observed in the liveborn and will be of particular interest to the practising physician. Surveys of the type described are expensive and difficult to organize: they are, nevertheless, crucial for a proper assessment of the pathological effect of individual chromosome abnormalities. The author raises the possibility that testicular failure in the infant male may have important effects on psychosexual behaviour in the mature individual. She also suggests that routine screening for chromosome abnormalities at birth would be a worth-while medical procedure.

The Society for the Study of Human Biology has performed a valuable service in publishing this compact and up-to-date review which will be of interest to all those concerned with human evolution and chromosome abnormality as a cause of developmental abnormality in man. At $£ 5.00$ it is very reasonably priced.

C. E. BLANK
Chromosome Hierarchy. An Introduction to the Biology of the Chromosome. By Bernard John and Kenneth R. Lewis. (Pp. viii $+171 ; 50$ Figures + 27 Tables. Paper covers: ${ }^{3} \cdot 50$; boards edition: f7.00.) London: Clarendon Press; Oxford University Press. 1975.

This book considers the structure, behaviour, and cellular functions of chromosomes, and their role in evolution. The chromosome is depicted as a hierarchy of interdependent genetic units, rising from nucleotide to genome, through codon, cistron, and linkage group.

The opening chapter discusses the molecular aspects of gene synthesis in relation to chromosome structure, including the effects of mutation. This is followed by a chapter on chromosome architecture which includes sections on the chemical composition, physical topography, and mechanical activities of chromosomes during nuclear division. The chapter on epigenetic activities illustrates the wide variety of control systems which have evolved at all levels of the genetic hierarchy as a means of regulating gene activity. In this interesting and informative chapter, sections on gene amplification, inactivation, and elimination at the chromosomal level are followed by a section on cell differentiation, in which hormones and chromosomal proteins are implicated in genetic control at the molecular level. The remainder of the book is devoted to the significance of chromosomal mutation in evolution and includes detailed coverage of the meiotic behaviour of structurally rearranged chromosomes.

The book is an erudite review of the elements of genetics, in which the chromosome is seen as the organizational hub of the hierarchy of hereditary units. It will be appreciated by those who already have a knowledge of genetics and cytogenetics, but it is not a text for the uninitiated. In this respect, the subtitle, 'An introduction to ...' may be misleading. The book will be of value to anyone who teaches cytogenetics, and to students who intend to specialize in the subject, but will be of limited interest to many readers of the fournal of Medical Genetics.

\section{A. MCDERMOTT}

Chromosomal Variation in Man. A Catalog of Chromosomal Variants and Anomalies. By Digamber S. Borgaonkar. (Pp. xvii +230. £8.25.) Baltimore and London: The Johns Hopkins University Press. 1975.

Chromosomal Variation in Man is intended to complement the McKusick's 'bible' on the Mendelian Inheritance in Man. A similar computerized system of cataloguing has been used and though the Johns Hopkins Press is the publisher in both instances, it is a pity that the quality of the production of Digamber Borgaonkar's book is not equal to McKusick's. Between the hard covers most of the book has been xerographed-or was this only a poor copy for the reviewer?

The book is unevenly divided into a section on the structural variation and anomalies of chromosomes (190 pages), numerical anomalies (20 pages), and chro- 
mosome breakage syndromes (2 pages). Extensive coverage seems to be the primary aim of this type of publication and it is the most complete catalogue of human chromosome variation there is to date. It should be, as the author hopes, the first source to be consulted when references on a specific chromosomal abnormality are sought.

The basic idea and cataloguing arrangement are good but Chromosomal Variation in Man will have to be regularly updated and extended to realize its full potential and become a chromosomal 'McKusick'.

\section{MichaEl Baraitser}

\section{New Chromosomal and Malformation Syndromes.}

Edited by Daniel Bergsma. Birth Defects: Original Article Series. Vol. XI. No. 5. (Pp. $\mathrm{x}+346$; illustrated. \$16.95.) The National FoundationMarch of Dimes. New York: Stratton Intercontinental Medical Book Corporation. 1975.

This is Vol. XI. No. 5 in the Birth Defects: Original Article Series and contains selected papers from a conference held in California in 1974. In a previous publication in this series called Malformation Syndromes (1974) the editor was criticized for the choice of title which misleadingly implied a comprehensive review of the subject. The present volume has thus been entitled New Chromosomal and Malformation Syndromes. Geneticists seem not only to be running out of titles for books, they are running out of titles for syndromes. In this edition we have the $3 \mathrm{M}$ syndrome (a name derived from the first letter of the surnames of three of the five authors-one can only feel sorry for the two left out), the KGB syndrome, the G syndrome, and the Floating Harbor syndrome.

What is clear from looking at the superb photographs is that despite all misgivings about the publication of conference papers, the clinical geneticist cannot see enough of the new malformation and chromosomal syndromes, because of the number of malformed infants he sees and is unable to diagnose.

The book is almost equally divided into the chromosomal and non-chromosomal malformation syndromes. There is the inevitable endeavour to describe recognizable syndromes associated with chromosomal abnormalities, and trisomy $9 p$ and trisomy 22 might qualify for recognition. Evidence is presented for the acceptance of three new short stature syndromes and among the better known entities, diagnostic criteria for 'the whistling face syndrome' are reviewed and the variable limb malformations in the de Lange syndrome are documented.

New Chromosomal and Malformation Syndromes is, like the loose-leaf series 'Syndrome Identification', another step forward in trying to make clinical meaning of the multitude of congenital malformations.

Michael Baraitser

Familial Polyposis Coli. Family Studies, Histopathology, Differential Diagnosis, and Results of Treatment. By H. J. R. Bussey. (Pp. xiii +104 ;
64 Figures +14 Tables. £6.60.) Baltimore and London: The Johns Hopkins University Press. 1975.

Clinical geneticists have been eagerly awaiting this book. The great experience of Dr Bussey in this field is unique, having been associated with Cuthbert Dukes at St Mark's Hospital from 1924. When he retired in 1974 he had been closely concerned with the investigation and recording of nearly 300 families with intestinal polyposes of all types. The book is somewhat disappointing in that it is much shorter than had been hopedonly about 100 pages including 64 figures and 14 tables. In addition Dr Bussey does not give his own personal opinion on several controversial aspects of the subject, but merely quotes the opposing theories. There is little discussion of the possible reasons for the remarkable $45 \%$ incidence of solitary cases, nor why in only 9 out of 99 of these patients presenting with a negative family history, did a child or other relative subsequently develop polyposis during a presumably lengthy followup period.

Notwithstanding these criticisms, the book is of great value. It contains many tables of data which reveal much about the condition. Dr Bussey's research has been connected mainly with the cancer aspect of the subject and the chapter on the relation to carcinoma is one of the high spots of the book. In these data $62.2 \%$ of the 293 patients presenting because of symptoms, already had malignant disease, and multiple carcinomata were found to be 12 times more frequently encountered in polyposis patients than in sporadic colonic cancer.

Dr Bussey sees the main value of the study of polyposis as the light it may throw on the wider problem of intestinal adenomas when solitary or few in number. $\mathrm{He}$ considers the suggestion that all adenomas of the large intestine have a genetic origin, though he does not rule out an interaction of environmental and genetic factors even in multiple polyposis families. The intriguing regression of rectal polyps after colectomy is discussed in this context.

For 25 years Gardner's syndrome has been regarded as a separate genetic entity, though the Swedish data of Thor Alm have thrown doubts on this by revealing many families in which only one of several polyposis members had an extracolonic lesion. The St Mark's data also contain 30 families in which only one member had the lesion of Gardner's syndrome. Nor was any difference found between the number of polyps and their distribution in polyposis families with and without Gardner's syndrome. Dr Bussey does not dismiss the idea that all adenomatous polyposis may be Gardner's syndrome with different degrees of manifestation of the subsidiary lesions.

The book is well written and the numerous photomicrographs are excellently reproduced. The references grouped at the end of the book are not comprehensive on the genetics of the subject, but are a useful collection on its neoplastic and clinical aspects. It can be recommended not only to clinical geneticists but also to gastroenterologists and surgeons who meet patients with 